\title{
信息技术环境下多元互动式教学模式应用研究 一一以《汽车驾驶与交通法规》为例
}

\author{
陈智娟 ${ }^{1}$ 王蒙蒙 \\ 1 河南工学院车辆与交通工程学院 2 河南工学院机械工程学院 \\ DOI:10.32629/mef.v2i5.121
}

[摘 要] 多元互动教学模式是以教师为主导, 以学生为主体, 以信息技术在教育教学领域的应用为依托的一种新型教学模 式。依照真实性、开放性、和谐性、时效性和启发性的原则,创设角色互换、游戏课堂、热点辩论等学习情境, 探索多元互 动教学模式在《汽车驾驶与交通法规》课程中的应用。实践证明多元互动教学模式可以有效提升教学效果, 以期为教学改 革提供参考。

[关键词] 信息技术; 多元互动教学模式; 学习情境; 教学效果

\section{Research on the Application of Multi-interaction Teaching Mode in Information Technology Environment — Taking the Vehicle Driving and Traffic Regulations as an Example}

Chen Zhijuan ${ }^{1}$ Wang Mengmeng ${ }^{2}$

1 Collage of Vehicle and Transportation Engineering, Henan Institute of Technology

2 Collage of Mechanical Engineering, Henan Institute of Technology

[Abstract] The multi-individual teaching mode is a new teaching mode based on teachers and taking students as the main body and relying on the application of information technology in the field of education and teaching. In accordance with the principles of authenticity, openness, harmony, timeliness and inspiration, to create learning situations such as role swaps, game classes, and hot debates, and explore the application of the multi-individual teaching model in the "Vehicle Driving and Traffic Regulations" course. Practice has proved that the multi-individual interactive teaching mode can effectively improve the teaching effect, in order to provide reference for teaching reform.

[Keywords] information technology, multiple interactive teaching mode, learning situation, teaching effect

\section{引言}

《汽车驾驶与交通法规》具有较强的科学性、应用性和 社会性, 是汽车相关专业的基础课程, 也是全校在校生的公 共选修课。在大班授课的现状下, 结合多媒体单一的、灌输 式的传统教学模式致使学生学习兴趣不高、参与度较低、学 习的主动性和积极性较弱, 教学效果不良。

多元互动教学模式是在信息技术快速发展的开放教育环 境下, 通过营造多边互动的教学环境, 在教学过程中实现师生 之间平等、多方面的互动, 激发学生的学习兴趣, 促使学生积极 主动学习和发展的一种新型教学模式。在《汽车驾驶与交通法 规》课程中, 科学运用多元互动教学模式, 有利于培养学生的创 新能力, 拓展学生的思维能力, 提高学生的知识应用能力。

\section{1 多元互动式教学模式的概念}

多元互动教学模式, 是在信息技术迅猛发展的开放式教 育环境下, 把教学活动看作是多元的交往沟通和动态的交互 影响过程, 通过深化和优化教学互动的方式, 充分利用各种 与学习相关的教学元素, 如人员元素、信息元素和物质元素 等, 调节各元素之间的关系和内在相互作用, 促进学生积极
主动学习与发展, 形成全方位、多层次的和谐互动, 以产生教 学共振、提高教学质量和效果的一种新型教学模式。多元互 动教学模式在传统教学模式的基础上进行改革创新, 以问题 为导向, 激发并维持学生的学习兴趣和动机, 促使学生带着 问题有目的性和针对性的进行学习和探讨; 通过教学过程中 各要素之间的互动, 拓展学生思维, 更好地培养学生的创新 能力、自主学习能力和终身学习的能力。

多元互动教学模式在实际教学过程中主要体现为在课 堂、课外活动场所及信息网络环境中的师生互动、生生互动 和生机互动, 旨在经由教师的引导、协调和促进, 使学生通过 探索、实践与合作, 完成新知识系统的建立。

\section{2 多元互动教学模式实施原则}

多元互动教学模式的具体实施, 需综合考虑学生学情、 课程性质、教学目标、教材内容等多方面因素, 遵循真实性、 开放性、和谐性、时效性和启发性的原则创设学习情境。

真实性原则。在多元互动教学模式中, 根据教学目标, 从学生角度出发, 引入贴近生活, 尤其是贴近校园生活的真 实性案例, 从而引发学生主动思考和分析, 并将自己置身于 
情境之中, 积极主动参与互动, 形成思维的碰撞, 在原有知 识、经验和能力的基础上, 学习新知识并实现知识的迁移, 从而构建新的知识体系。

开放性原则。多元互动教学模式下, 学生是教学过程的 主体, 学习情境的创设要在充分发挥学生主体作用的基础上, 变被动学习为主动学习, 即以开放性的学习资源、多样化的 互动形式、不确定的互动过程为前提创设学习情境, 培养学 生积极学习的态度、自主学习的能力和勇于创新的意识。

和谐性原则。教学实践证明, 教学成败的关键并不完全 在于教师的专业知识水平和教学技巧, 还取决于师生关系、 教师对学生的态度。多元互动教学模式倡导建立平等的师生 互动关系, 教师要尊重学生的人格和经验, 尽力营造宽松和 谐的互动氛围, 使学生敢想、敢言、各抒己见。

时效性原则。一是在学习情境中引用较新的案例, 导入 贴近热点的问题, 激发学生参与互动的热度, 体现理论知识 在实际生活中的应用, 提升学生对课程学习的认同度; 二是 及时纠正教学过程中出现的 “离散” 或 “偏题” 现象, 确保 互动过程的有效性, 提高学生的学习效率。

启发性原则。在教学过程中充分发挥教师的引导作用, 以任务为驱动, 通过提供思维方法、搭建知识阶梯、提示思 考角度等方法, 引导学生进行自主学习, 实现师生、生生和生 机之间有效的、个性化的互动, 从而产生教学共振, 提高教学 效果, 同时帮助学生形成适合自己的高效的学习方法和解决 问题的方法。

\section{3 多元互动教学模式在课程中的应用}

《汽车驾驶与交通法规》课程共计 20 学时, 结合教学内容 安排, 创设角色互换、游戏课堂、热点辩论、知识抢答和课题 调查学习情境, 并蕴含有矛盾和疑惑, 促使学生在原有知识结 构的基础上进行深入探究, 为多元互动教学的开展奠定基础。

表 1 学习情境创设及教学安排

\begin{tabular}{|c|c|l|}
\hline 周次 & 学习情境 & \multicolumn{1}{|c|}{ 柔盾或疑惑 } \\
\hline 1 & \multicolumn{2}{|c|}{ 分组及任务布置 } \\
\hline 2 & 角色互换 & 调研汇报: 驾驶员/道路交通环境与交通安全的关系 \\
\hline 3 & 角色互换 & 调研汇报: 道路交通信号及通行规定 \\
\hline 4 & 游戏课堂 & 道路交通信号辨识赛 \\
\hline 5 & 知识抢答 & 道路交通安全知识抢答 \\
\hline 6 & 角色互换 & 调研汇报: 交通事故的处理与法律责任 \\
\hline 7 & 角色互换 & 调研汇报: 汽车驾驶基本技术 \\
\hline 8 & 热点辩论 & 辩论主题: 公交车应不应该加装司机隔离门 \\
\hline 9 & 角色互换 & 调研汇报: 交通事故中伤员抢救常识 \\
\hline 10 & 课题调查 & 课程总结及评价 \\
\hline
\end{tabular}

角色互换。角色互换学习情境的创设, 需教师对教学内 容进行详细的分析和分解, 选取较为简单、易于实践的内容, 便于学生自主学习、自行设计和开展教学活动, 增强其对知 识点的理解, 提升其语言表达能力和动手实践能力。

具体实施步骤: 学生根据教师给定的主题, 通过查阅资 料、问卷调查、实地考察等方法, 完善教学方案设计、制作 教学课件, 面向教师及其他学生汇报调研成果。汇报结束后,
其他同学就汇报内容中存在的疑问进行提问、探讨和交流, 并给出评价; 教师则要对调研及汇报过程给予科学客观的评 价, 表扬其闪光点, 增强其自主学习的信心和积极性, 纠正其 不足, 更新其知识架构。

游戏课堂。即将游戏与教学内容通过一定的规则有机的 结合在一起, 将教学内容潜移默化的融入到游戏中, 激发学 生的学习兴趣, 提高学生的学习能力, 其核心是 “寓教于乐”、 “润物无声”。

具体实施步骤: 教师结合教学内容设置游戏形式, 制订 游戏规则。游戏方式要便于组织和实施, 易于创造生生互动 的环境; 游戏规则要注重教学过程, 促使学生在游戏过程中 自发、自觉的交流和学习。最后通过 “闯关”、“积分”、“挑 战”等方式完成对游戏教学过程的评价, 对学生小组团队和 个人进行评价。

热点辩论。建立课程教学内容与当下社会热点之间的联 系, 创设辩论学习情境, 培养学生自主收集和整理资料的能 力, 训练学生语言表达能力, 锻炼学生善于倾听的品质, 提升 学生知识应用的能力。

具体实施步骤: 结合与课程内容相关的社会热点或與论, 设置辩论主题并说明辩论程序, 使其尽可能贴近正规化的辩 论赛, 为学生创造协作与竞争的氛围; 辩论过程中适时恰当 地纠正学生产生的 “偏题” 现象, 鼓励学生突破思维定势, 拓宽思路; 引入观众提问环节, 进一步扩大互动对象范围; 辩论结束后及时采取观众投票的形式评选优胜队和最佳辩 手, 并将结果纳入过程评价。

知识抢答。以课程教学内容为基础, 将难点和重点作为 考察内容, 创设知识抢答学习情境, 全面考核学生对知识点 的掌握情况。

具体实施步骤：借助 “雨课堂”、“超星” 等信息化技术 手段, 设置有关道路交通安全相关的问题, 学生通过手机在 限定的时间内给出答案; 分别记录小组总成绩和个人成绩, 并将成绩纳入过程评价。知识抢答学习情境有效地将知识性 和趣味性融为了一体, 在竞赛的氛围中强化了学生对知识点 的认知和掌握。

课题调查。该学习情境的创设, 既可为全面检测学生对 本课程知识的掌握情况提供依据, 又有利于培养学生综合应 用知识的能力、团队协作精神和初步的科学研究的能力, 为 将来的职业生涯奠定基础。

具体实施步骤: 完成理论知识学习后, 以小组为单位组 织开展相关课题调查, 可选择优化 “角色互换” 课题, 亦可综 合课程内容选择新课题。按照搜集资料-整理资料-分析资料 -概括结果的思路和程序完成课题调查, 形成调查报告, 调查 报告作为结果评价的重要依据。

\section{4 教学效果分析}

多元互动教学模式已在河南工学院《汽车驾驶与交通法 规》课程中连续应用两个学期, 在课程评价体系、学生综合 成绩和学生素养与能力方面均取得了可观的成果。 
评价体系逐步健全。多元互动教学模式下所形成的评价 体系其评价主体是多元的, 既包含教师对学生所完成任务的 评价, 学生对教师教学理念、教学方法和教学过程设计的评 价, 也包含学生与学生之间的互评、学生对教材等学习资料 的评价, 且评价主体在评价过程中处于平等地位。评价形式 是多样的, 利用信息化技术全程记录学生自主学习、课堂教 学和各互动环节过程, 并将记录结果按照一定的比例纳入过 程评价, 同时将课题调查报告纳入结果评价, 学生最终的综 合成绩为过程评价和结果评价的有效组合; 学生对教师和学 习资料的评价贯穿于整个教学过程, 经过一定阶段的教与学, 教师要根据多向反馈信息和评价信息, 分析教学中存在的问 题, 及时调整教学行为、改进教学方法。

教学效果显著提升。2018-2019学年第一学期是探索多元 互动教学模式在《汽车驾驶与交通法规》课程中应用的第一 学期, 对比分析该学期与上学期学生本课程的综合成绩可以 看出, 多元互动教学模式下, 学生成绩结构更加合理, 优良率 较传统教学模式下提高了 $7 \%$, 不及格率降低了 $1.2 \%$; 从师生对 课程的教学评价成绩来看, 在教学内容相差不大的前提下, 多 元互动教学模式下的教学方法、教学效果明显优于传统教学 模式。综合看来, 多元互动教学模式相较于传统教学模式更加 适用于《汽车驾驶与交通法规》课程, 其教学效果更加明显。

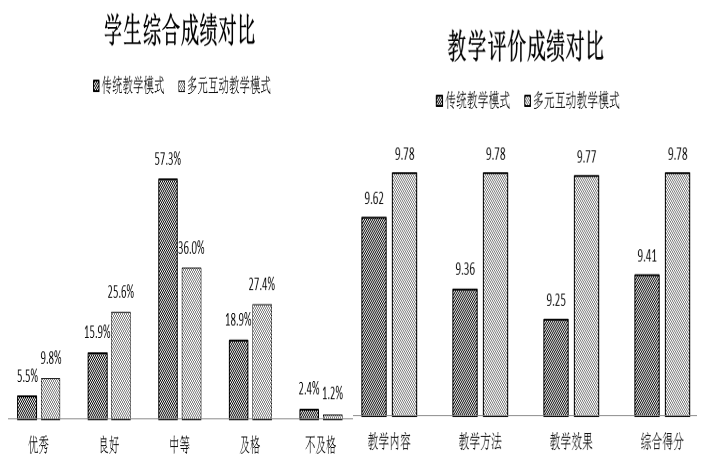

图 1 学生综合成绩和教学评价成绩对比
学生情智明显提高。多元互动教学模式下的教学过程是 一个学生情智得以全面提升的学习过程。学生只有经过自主 学习, 产生疑惑或拥有自己的思想和观点后, 才能参与多元 互动的过程中去, 才能实现思想的交流、碰撞, 才能逐步构建 新的知识体系; 丰富而又有意义的多元互动过程, 为学生提 供了多样的才艺展示机会, 促进学生德智美的全面发展; 调 研汇报、课题调查等学习情境, 要求学生主动走进生活、走 向社会, 面对各种错综复杂的问题, 培养了其主动解决问题 的能力, 激发了其作为当代大学生的社会责任感。

\section{5 结束语}

多元互动教学模式在《汽车驾驶与交通法规》课程中 的探索应用, 真正实现了以学生为教学主体, 增强了学生自 主学习、查阅资料、语言交流、互助协作等多方面的能力, 有效提升了课程的教学质量和效果。但大班课仍旧存在课 堂管理困难的问题, 仍需教师根据教学内容高效、有秩序的 组织学生开展多元互动, 以期将其在课程中的应用发挥到 极致。

\section{[参考文献]}

[1]李桂峰,肖春玲, 高誉嘉.基于网络环境食品营养学课 程多元互动教学模式构建及应用效果 [J]. 现代农业科 技,2013,(15):341-342.

[2]张善军.信息技术环境下大学英语多元互动教学模式 研究[D].上海外国语大学,2011,(5):118.

[3]陈营,张严秋.大学英语 “多元互动” 式教学模式的探 索[J]. 重庆科技学院学报(社会科学版),2010,(08): 198-199.

[4]余乐. “多元互动” 教学模式的研究与实践探索 [J]. 内蒙古电大学刊, 2007, (04):81-82.

作者简介：

陈智娟(1990--), 女, 河南长垣人, 汉族, 硕士, 助教, 研究方 向: 交通管理与规划、道路交通安全、汽车运用工程。 